\section{A genuine global collaboration}

SIR - In his recent Commentary article entitled "A genuine global partnership?" (Nature 346, 692; 1990), S. S. Yamamoto expresses concern about the proposed Japanese participation in the Superconducting Super Collider (SSC) project. He refers to 91 Japanese physicists who "have agreed to participate in the SSC project", but suggests that they "will be paying an entrance fee to join the project without being able to make significant scientific contributions".

The 91 physicists to whom Yamamoto refers have joined the Solenoidal Detector Collaboration (SDC) which is preparing the design of a major detector for the SSC. As the spokesman for that collaboration, I would like to comment on the role being played by its Japanese members and correct some possible misunderstandings.

The SDC, formed about a year ago, brought together four separate groups of physicists working independently on similar detector concepts. Three of those groups were in the United States and the fourth in Japan. Japanese high-energy physicists had held a series of workshops, and their design efforts were the most advanced of any of the four groups. From the beginning, it was clear that, even more than financial capital, intellectual capital was needed, and Japanese intellectual capital has been crucial to our collaborative efforts. Indeed, the Japanese collaborations are making major technical and scientific contributions to the detector design, as well as playing an important role in the overall leadership.

Yamamoto states that "although the United States invites foreign participation where money and manpower are concerned, to the best of my knowledge they do not invite participation on an equal basis in scientific, technical and administrative matters". I cannot speak for the United States, but I can speak for the collaboration with which the 91 Japanese physicists are associated. The management of our colllaboration consists of a spokesman and three deputy spokespersons (from the United States, from Europe and from Japan). Our governing board has 17 individuals, ten from the United States, two from Europe and five from Japan. We have numerous technical committees, each with several cochairpersons - in all cases but one there is a Japanese co-chairperson. The oral presentation, made to the SSC Laboratory Program Advisory Committee on behalf of our detector concept, was divided between two people, the SDC Japanese deputy spokesperson and myself. To put all of this in perspective, our 91 Japanese collaborators represent about 20 per cent of the present total membership of the SDC, although they have made a substan- tially larger fraction of the contributions (scientific and technical) to the work.

One major obstacle comes from the geographical dispersal of the collaborators, and the substantial travel costs in both time and money. But we can communicate almost instantaneously by electronic mail, and we hope that, in the near future, video-conference technology will permit frequent meetings between collaborators all over the globe.

On financial support, we are hoping to build an ambitious detector, and the costs will be high. This collaboration, if it is to fulfil its aspirations, needs financial support from Japan and from other non-US collaborators, and of course, it expects support from the US government. In large part, the Japanese contribution to the detector is likely to involve the design and fabrication in Japan of major pieces. To Yamamoto's advice that "the US government and high-energy physics community should insist that the Japanese contribution is scientific as well as financial", I can only say that this insistence is not necessary. Our Japanese colleagues, with many distinguished scientists among them, would not have it any other way.

As a citizen of the international highenergy physics community, I want to express my full agreement with Yamamoto that the continued development of future high-energy accelerator projects in Japan is indeed very important. At the same time, about a third of the Japanese experimental high-energy physics community is sufficiently excited by the scientific opportunities offered by the SSC to have invested a large amount of time and effort in beginning the preparation of SSC experiments. I share that excitement and I hope that with the support of the Japanese scientific community the Japanese government will find it possible, and indeed desirable, to provide the resources needed to bring these outstanding efforts to fruition.

GEORGE H. TRILLING

University of California,

Berkeley, California 94720, USA

\section{Group theory}

SIR-British science and technology have until recently had an enviable record of innovation. We think this is due to the fact that they have been run on well tried and, until recently, trusted principles of 'backing the man'. Although this principle may have been elitist, it meant that science and technology were done by the individuals who knew their subject and were left to get on with the job.

The results speak for themselves. During a period of about 300 years, British
Lawrence Berkeley Laboratory scientific institutions and in this century, the research councils have operated on the basis of "powerful informality", as one US philosopher put it, by backing individual thinkers whose work made significant contributions to science and consequently, to society as a whole. This approach paid for itself many times over and gave our system of science funding a world reputation second to none.

It is with some consternation, therefore, that we observe how deeply the recent politico-economic panic has affected the research councils and university funding bodies. First, there has been a change from 'backing the man' to backing the group (the takeover fallacy). It needs real knowledge to judge new ideas but anyone can count heads. Second, the Science and Engineering Research Council (SERC) is now asking for "estimates of proposed cash flow" as if the scientist were proposing to open a fastfood franchise and count the number of hamburgers crossing his counter. It seems that the council is being taken over by amateur accountants with attitudes of starry-eyed simplicity.

But the 'bottom line' is surely in the latest SERC guidelines for research applicants, where we are asked to "assume that the reader (of the grant application) knows very little about the subject"! What kind of refereeing is this? Quis custodiet ipsos custodes?

F. BROWN N. G. MAROUDAS

Department of Microbiology,

University of Surrey,

Guildford,

Surrey GU2 5XH.

\section{Women at work}

SIR-At a recent primatology conference, organized at the University of California, Santa Cruz, only women were invited or allowed to attend. This highlights an important, but avoidable, problem in all scientific work: the experimenter effect or experimenter bias.

This occurs when an experimental outcome is not the result of the manipulation of independent variables, but rather results from some (typically) unintentional act or actions of the experimenter or experimenters. Scientific conferences should also be organized so as to ensure the accurate and reliable gathering, analy. sis and distribution of information. To conduct a scientific conference in 1990 from which male participants are excluded seems to imply that the results obtained, like an experiment confounded by experimenter bias, should be viewed with caution.

Department of Psychology

Washington University,

St Louis, Missouri 63130, USA 